\title{
Dermatoglyphic Patterns in Children with Chronic Constipation
}

\author{
ROBERT A. DRONGOWSKI, MS and ARNOLD G. CORAN, MD
}

\begin{abstract}
Analysis of the fine ridge configurations on the digits of the palms and soles (dermatoglyphics) may sometimes help in the diagnoses of certain medical disorders. Dermatoglyphic patterns have been reported to be associated with congenital anomalies, such as congenital heart disease, duodenal ulcer, abdominal pain, and constipation. The palmar dermatoglyphic patterns of 77 children with constipation (39 functional and 38 organic constipation) were recorded. The control group consisted of 84 children with inguinal hernia. Those patients with at least one arch identified on any digit of either hand were termed arch positive. There was no significant correlation between arch positivity and constipation (functional or organic), or inguinal hernia (chi square, $P=0.9211$ ). Therefore, the presence of palmar arches cannot be used as a screening device for children with chronic constipation, especially of organic etiology.
\end{abstract}

KEY WORDS: fingerprints; constipation; abdominal pain; dermatoglyphics.

Dermatoglyphic patterns, an analysis of the fine ridge configurations on the digits of the palms and soles, theoretically could be used in the diagnostic evaluation of certain medical disorders, since formation of these patterns is under genetic influence $(1,2)$. Since Galton (3) first systematically studied fingerprints and identified the fundamental formations (arches, loops and whorls), it has been established that certain dermatoglyphic patterns are associated with a number of congenital anomalies (4-9).

A recent report has documented that a specific fingerprint pattern (arches) is seen in association with constipation and abdominal pain. These authors claimed that the fingerprint pattern was useful in distinguishing between functional constipation and constipation secondary to various organic disorders

Manuscript received November 18, 1994; revised manuscript received February 3, 1995; accepted March 27. 1995.

From the Section of Pediatric Surgery, C.S. Mott Children's Hospital and University of Michigan Medical School, Ann Arbor, Michigan.

Supported in part, by NIH grant M01RR00042.

Address for reprint requests: Robert Drongowski, F3970 Mott Hospital, University of Michigan, Ann Arbor, Michigan 481090245 .
(10). Since we treat a large number of children with constipation (11), we decided to analyze the dermatoglyphic patterns in these patients in an attempt to confirm or refute the above reported association (arches).

\section{MATERIALS AND METHODS}

The palmar dermatoglyphic patterns of 161 children with a primary diagnosis of either inguinal hernia ( $N=84$, controls) or constipation (functional, $N$ $=39$; organic, $N=38$ ), seen in the pediatric surgery clinic, were examined. Each digit print was recorded as either an arch, whorl, or ulnar or radial loop (12). Each patient's fingers were examined with a handheld magnifying glass and permanent records were obtained by using either a standard photocopying machine or the 3M Identifier System (St. Paul, Minnesota), an inkless fingerprint system.

Following each patient's clinic visit, his/her hospital record was reviewed for the following information: previous medical history, sex, and age. Patients were divided into the following groups: functional constipation $(N=39)$, organic constipation $(N=38)$, 
Table 1. Distribution Of Arches In Patients With Inguinal. Hernia and Organic Or Functional Constipation*

\begin{tabular}{lcc}
\hline & \multicolumn{2}{c}{ Arch positive } \\
\cline { 2 - 3 } & Yes $(\mathrm{N}, \%)$ & No $(\mathrm{N}, \%)$ \\
\hline Inguinal hernia & & \\
$(N=84)$ & $25(29.8)$ & $59(70.2)$ \\
Chronic constipation & Yes $(\mathrm{n}, \%)$ & No $(\mathrm{n}, \%)$ \\
Functional $(N=39)$ & $13(33.3)$ & $26(66.7)$ \\
Organic $(N=38)$ & Yes $(\mathrm{n}, \%)$ & No $(\mathrm{n}, \%)$ \\
& $12(31.6)$ & $26(68.4)$ \\
\hline
\end{tabular}

${ }^{*}$ Chi square, 2-3 contingency table; $P=0.9211$.

[secondary to Hirschprung's Disease $(N=17)$, imperforate anus $(N=15)$ and other intestinal malformations $(N=6)]$ and inguinal hernia $(N=84)$. Constipation was defined as a bowel frequency of less than once every two days with associated fecal incontinence for a period of no less than three months. All patients with constipation were referred to the pediatric surgical service following failed treatment by their referring physicians. Patients with inguinal hernia had a negative history of constipation determined by hospital record review.

Children were further subdivided into arch positive, ie, those having at least one arch identified on any digit of either hand, and arch negative, ie, those having any combination of loops and/or whorls on all 10 digits.

Informed consent was obtained from the parents in accordance with the standards established by the $\mathrm{Hu}$ man Use Committee prior to data collection.

Statistical analysis was performed on the Michigan Interactive Data Analysis System (MIDAS), using analysis of variance and chi-square contingency table analysis with $P<0.05$ considered significant.

\section{RESULTS}

There was no statistically significant correlation between arch positivity and functional constipation, organic constipation, and inguinal hernia $(P=$ 0.9211) (Table 1).

There were no significant differences in mean age between the three study groups $(P=0.1822)$. Additionally, no significant correlation between arch positivity and sex was evident $(P=0.1607)$ (Table 2$)$.

\section{DISCUSSION}

Numerous studies have attempted to correlate dermatoglyphic patterns with various medical conditions, both congenital $(1,4-6)$ and acquired $(7,13,14)$ in origin. The rationale behind such inquiry is obvious: a
Table 2. Age and Sex In Patients With Inguinal Hernia and Organic Or Functional Constipation

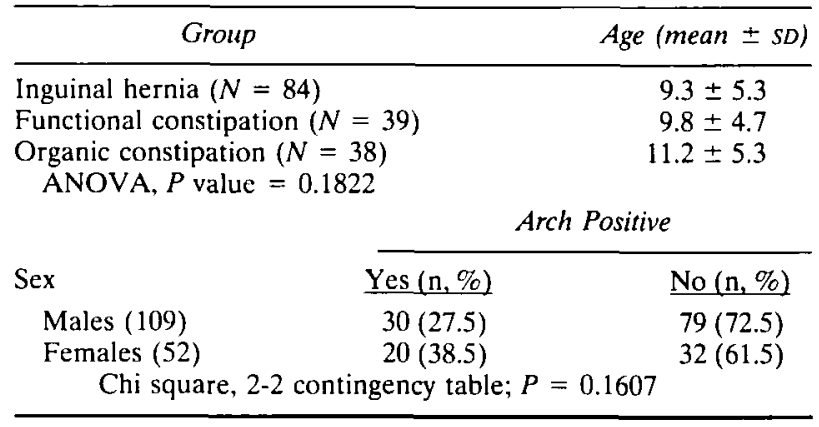

quick, noninvasive method with which to screen patients suspected of having some predisposition to a variety of diseases. However, in spite of the fact that several papers have been published demonstrating a correlation between dermatoglyphic patterns and specific medical conditions, including sexual dimorphism $(15,16)$, the practical application of dermatoglyphics to medical diagnosis has not occurred. This is probably due, in large part, to skepticism by the medical community, a lack of well-controlled confirmatory studies, and the fact that several investigators defined a large number of medical conditions that could be categorized by dermatoglyphic patterns, thus ensuring nonspecificity. Follow-up studies to confirm the association of dermatoglyphic patterns with such disorders as duodenal ulcer (7), rubella (8), fetal wastage (17), pseudohypoparathyroidism (4), and congenital heart disease (9) have been rare. However, a study of dermatoglyphics and leukemia (18) failed to confirm the association of leukemia with a variety of unusual dermatoglyphic patterns reported by previous investigators $(19,20)$.

Since our general pediatric surgery practice involves the care of a large number of children with chronic constipation (12), the study correlating dermatoglyphic patterns with early-onset constipation and abdominal pain aroused our interest (10). However, in our study, no statistical correlation between arches and functional or organic constipation could be shown.

Correlations with sexual dimorphism $(15,16)$ have been previously reported; however, our study did not show any significant sex differences in the fingerprint analysis.

In conclusion, this study has demonstrated that no significant correlation exists between dermatoglyphic patterns and constipation, both functional and organic. Therefore, the presence of arches on any digit 
of either hand cannot be used as a screening device for organically caused constipation.

\section{REFERENCES}

1. Alter M: Dermatoglyphic analysis as a diagnostic tool. Medicine 46:35-56, 1966

2. Cummins H, Midlo C: Fingerprints, Palms and Soles. New York, Doyer, 1961

3. Galton F: Fingerprints. London, Macmillan, 1892

4. Forbes AP: Fingerprints and palm prints (dermatoglyphics) and palmar-flexion creases in gonadal dysgenesis, pseudohypoparathyroidism and Klinefelter's syndrome. $\mathrm{N}$ Engl J Med 270:1268-1277, 1964

5. Preuss M, Fraser FC: Dermatoglyphics and syndromes. Am J Dis Child 124:933-943, 1972

6. Crawfurd $\mathrm{M}$ : Dermatoglyphics in partial $\mathrm{C}$ trisomics. Lancet 1:1195-1196, 1968

7. Habibullah CM, Mujahid M, Shivaprakash M, Iqbal MA, Ishaq $M$ : Fingertip and palmar patterns in duodenal ulcer. Hum Hered 32:432-434, 1982

8. Swartz MH, Herman MV, Teichholz LE: Dermatoglyphic patterns in patients with mitral valve prolapse: A clue to pathogenesis. Am J Cardiol 38:588-593, 1976

9. Sanchez Cascos A: Finger-print patterns in congenital heart disease. Br Heart J 26:524-527, 1964

10. Gottlieb SH, Schuster MM: Dermatoglyphic (fingerprint) evi- dence for a congenital syndrome of early onset constipation and abdominal pain. Gastrocnterology 91:428-432, 1986

11. Katz C, Drongowski RA, Coran AG: Long-term management of chronic constipation in children. J Pediatr Surg 22:976-978, 1987

12. Hall JG, Froster-Iskenius UG, Allanson JE: Dermatoglyphics and trichoglyphics. In Handbook of Normal Physical Measurements. Oxford, Oxford University Press, 1989

13. Miller JR, Giroux J: Dermatoglyphics in pediatric practice. J Pediatr 69:302-312, 1966

14. Achs R, Harper RG, Sicgel M: Unusual dermatoglyphic findings associated with Rubella embryopathy. N Engl J Med 274:148-150. 1966

15. Balgir RS: Dermatoglyphic studies in affective disorders: An appraisal. Biol Psychiatry 17:69-82, 1982

16. Penrose LS: Memorandum on dermatoglyphic nomenclature. Birth Defects 4:1-13, 1968

17. Rose LI, Gabbe SG, Teichholz LE, Villee DB, Williams GH: Dermatoglyphics associated with fetal wastage. $N$ Engl J Med 287:451-452, 1972

18. Berka L, McClure PD, Sonley MJ, Thompson MW: Dermatoglyphics in childhood leukemia. Can Med Assoc J 105:476482. 1971

19. Verbov JL: Dermatoglyphics in leukaemia. J Med Genet $7: 125-131,1970$

20. Rosner F: Dermatoglyphics in leukacmia. Lancet 2:882-883, 1970 